\title{
Dummy-surface molecularly imprinted polymers on magnetic graphene oxide for rapid and selective quantification of acrylamide in heat- processed (including fried) foods
}

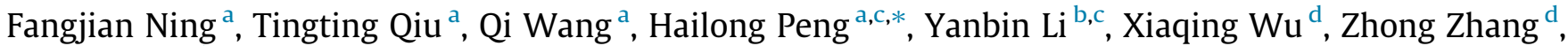 \\ Linxin Chen ${ }^{\mathrm{d}}$, Hua Xiong ${ }^{\mathrm{a}, *}$ \\ a State Key Laboratory of Food Science and Technology, Nanchang University, Nanchang 330047, China \\ ${ }^{\mathrm{b}}$ College of Biosystem Engineering and Food Science, Zhejiang University, Hangzhou, Zhejiang 310058, China \\ ${ }^{\mathrm{c}}$ Department of Biological \& Agricultural Engineering, University of Arkansas, Fayetteville, AR 72701, USA \\ ${ }^{\mathrm{d}}$ Yantai Institute of Coastal Zone Research, Chinese Academy of Sciences, Yantai 264003, China
}

\section{A R T I C L E I N F O}

\section{Article history:}

Received 21 July 2015

Received in revised form 6 October 2016

Accepted 22 October 2016

Available online 24 October 2016

\section{Keywords:}

Acrylamide

Magnetic nanoparticles

Graphene oxide

Dummy surface molecular imprinting

\begin{abstract}
A B S T R A C T
Novel nano-sized dummy-surface molecularly imprinted polymers (DSMIPs) on a magnetic graphene oxide $\left(\mathrm{GO}-\mathrm{Fe}_{3} \mathrm{O}_{4}\right)$ surface were developed as substrates, using propionamide as a dummy template molecule for the selective recognition and rapid pre-concentration and removal of acrylamide (AM) from food samples. These products showed rapid kinetics, high binding capacity (adsorption at $3.68 \mathrm{mg} \cdot \mathrm{g}^{-1}$ ), and selectivity (imprinting factor $\alpha 2.83$ ); the adsorption processes followed the Langmuir-Freundlich isotherm and pseudo-second-order kinetic models. Excellent recognition selectivity toward acrylamide was achieved compared to structural analogs, such as propionic and acrylic acids (selectivity factor $\beta$ 2.33, and 2.20, respectively). Moreover, DSMIPs-GO- $\mathrm{Fe}_{3} \mathrm{O}_{4}$ was used to quantify acrylamide in food samples, yielding satisfactory recovery (86.7-94.3\%) and low relative standard deviation $(<4.85 \%)$. Thus, our DSMIPs-GO- $\mathrm{Fe}_{3} \mathrm{O}_{4}$-based procedure was demonstrated to be a convenient and practical method for the separation, enrichment, and removal of acrylamide from food samples.
\end{abstract}

(c) 2016 Elsevier Ltd. All rights reserved.

\section{Introduction}

Acrylamide (2-propenamide), a small unsaturated amide molecule, has been used in the oil, cosmetics, water treatment, and textile industries since the mid-1950s. Acrylamide has been demonstrated to be a neurotoxic compound that has also been identified as a probable human carcinogen (group 2A) and genotoxicant (IARC., 1994). In 2002, the Swedish National Food Agency and Stockholm University reported that large amounts of acrylamide could be found in certain thermally processed foods especially potato products, coffee, and breakfast cereals, exceeding the guideline threshold $\left(0.5 \mu \mathrm{g} \cdot \mathrm{L}^{-1}\right)$ for acrylamide in drinking water, as proposed by the WHO (Swedish National Food Administration., 2002). Acrylamide is known to form via the Maillard reaction during heating of starchy food. Methods in which the temperature exceeds $120^{\circ} \mathrm{C}$, such as baking, frying, grilling, and toasting, can cause the amino acid asparagine (found in certain

* Corresponding authors at: State Key Laboratory of Food Science and Technology, Nanchang University, Nanchang 330047, China.

E-mail addresses: peng_hailong@aliyun.com (H. Peng), huaxiong100@126.com (H. Xiong) food products) to react with reducing sugars via the Maillard reaction to produce acrylamide (Donald, Bronislaw, \& Andrew, 2004; Mendel, 2003). Considering the toxicity of acrylamide, the rapid and sensitive detection of this compound in food has become a crucial issue for food safety.

In recent years, several analytical methods have been developed for detection of acrylamide including enzyme-linked immunosorbent assays (ELISAs), high-performance liquid chromatography (HPLC), liquid chromatography- with mass spectrometry (LCMS), gas chromatography- with mass spectrometry (GC-MS), and LC-MS/MS (Mastovska \& Lehotay, 2006; Milan, Daniel, Iva, \& Fernando, 2014; Zhang et al., 2014). Among these methods, ELISA is a rapid, robust, and high-throughput analytical alternative to the instrumental methods used in trace analyses of food and environmental samples. However, ELISA has certain drawbacks, such as the high cost and instability of antibodies (Wang, Quan, Lee, \& Kennedy, 2006). Furthermore, GC-MS, LC-MS, and LC-MS/MS are relatively expensive and cannot be easily adopted by nonspecialized laboratories. In contrast, HPLC with UV detection has the advantages of simplicity, and low cost in comparison with MS techniques. Notably, however, the matrix effect of HPLC is a 
serious problem in the trace analysis of acrylamide in complex matrices, such as food, thereby hindering identification and quantification of acrylamide. Thus, elimination of this matrix effect by sample pretreatments, such as solid-phase extraction (SPE) or solid-phase microextraction (SPME), are of considerable importance in trace analysis. However, the traditional sorbents of SPE/ SPME have several drawbacks, such as low selectivity and adsorption capacity (Carpinteiro et al., 2004). Therefore, there is a need for development of specific materials with high selectivity and adsorption. Molecularly imprinted polymers (MIPs) are gaining popularity because of their high adsorption capacity, high selectivity, low cost, and ease of preparation; MIPs have been widely applied to trace analysis pre-concentration and separation in diverse fields, such as natural, agricultural, and food products, as well as environmental samples (Chen, Xu, \& Li, 2011). The potential advantages of MIPs include desirable selectivity, physical robustness, low cost, thermal stability, and excellent reusability (Ning, Peng, Dong, Zhang, \& Xiong, 2014). MIPs have attracted increasing interest in numerous fields, particularly for SPE and chromatographic separation, because of these advantages. However, the traditional method for production of MIPs has several disadvantages, including complicated after-treatment workup, heterogeneous binding sites, low binding capacity, and slow mass transfer ( $\mathrm{Hu}$ et al., 2014).

Surface imprinting allows the presence of imprinted sites in the supporting material's surface, ensuring complete removal of templates, low mass-transfer resistance, and easy access to target molecules. Surface imprinting over nanosized support materials with large specific surface area is suitable for achievement of high binding capacity (Xie et al., 2015). Graphene oxide (GO) possesses an extremely large specific surface area and small dimensions, and these characteristics make it an excellent candidate for a support material to prepare surface MIPs. The use of MIPs on a GO surface (MIP-GO) has been proposed previously. MIP-GO shows high loading capacity and short binding time for template molecules $(\mathrm{Li}, \mathrm{Li}$, Dong, Qi, \& Han, 2010; Luo, Jiang, \& Liu, 2013). However, MIP-GO disperses homogeneously in solution and is difficult to separate by traditional centrifugation and filtration methods; this situation restricts its applications to some extent. Magnetic nanoparticles $\left(\mathrm{Fe}_{3} \mathrm{O}_{4}\right)$ show superparamagnetic and magnetic characteristics; for this reason, they can be easily separated from a solution using an external magnetic field. Because of the advantages of GO and $\mathrm{Fe}_{3} \mathrm{O}_{4}, \mathrm{GO}-\mathrm{Fe}_{3} \mathrm{O}_{4}$ composites have been developed and applied in the field of MIPs (Ning, Peng, Li, Chen, \& Xiong, 2014; Lin et al., 2015). However, MIPs have not been reported for acrylamide because acrylamide often acts as a functional monomer to recognize template molecules in the traditional molecular imprinting technology. Moreover, the double bond of acrylamide is crosslinked during preparation of MIPs, resulting in the failure to be cleared off by eluents. Additionally, the high toxicity of acrylamide raises safety concerns. Dummy surface molecular imprinting techniques (DSMITS) are an effective way to overcome these shortcomings in the preparation of AM-MIPs.

At present, DSMITs involve the use of structural analogs of the target compounds as template molecules to address the problem of template leakage. However, these could also provide an attractive alternative in the following situations: when the original template is very expensive or safety considerations are involved in its manipulation, when the polymerization conditions can result in unwanted compound degradation, or when low solubility of the target analyte does not allow for its use in the synthesis of MIPs (Chen, Li, Zhao, Chang, \& Qi, 2014; Xu, Lu, Li, \& Chen, 2013).

On the basis of the aforementioned studies, propionamide (PM), which is a structural analog of acrylamide, was selected here as a dummy template molecule. Acrylic acid (AA) and ethylene glycol dimethacrylate (EGDMA) were selected as the functional monomer and crosslinker, respectively, and were combined with DSMITs to prepare acrylamide dummy surface MIPs (AM-DSMIPs-GO-Fe ${ }_{3}$ $\mathrm{O}_{4}$ ) in this work. The $\mathrm{GO}-\mathrm{Fe}_{3} \mathrm{O}_{4}$ surface was coated with AMbased MIPs to achieve high imprinting efficiency and binding capacity. GO was used to improve the adsorption capacity, and $\mathrm{Fe}_{3} \mathrm{O}_{4}$ nanoparticles were used for separation. To the best of our knowledge, this study represents the first successful use of DSMITs to prepare AM-DSMIPs-GO-Fe $\mathrm{O}_{4}$ for pre-concentration of acrylamide in food matrices.

\section{Experimental procedures}

\subsection{Materials and instruments}

Acrylamide (AM), propionamide (PM), propionic acid (PA), acrylic acid (AA), acetic acid (HAc), L-asparagine L-Asn), 6aminocaproic acid (ACA), 2, 2-azobisisobutyronitrile (AIBN), and ethylene glycol dimethacrylate (EGDMA) were purchased from Aladdin (Shanghai, China). Ferric chloride hexahydrate $\left(\mathrm{FeCl}_{3} \cdot 6 \mathrm{H}_{2}-\right.$ $\mathrm{O})$, graphite powder, ethylene glycol and sodium acetate (NaAc) were purchased from Sinopharm Chemical Reagent Co., Ltd (Shanghai, China). Other reagents were analytically pure and used without further purification.

Fourier transform infrared (FT-IR) spectra were recorded using an FT-IR Nicolet 5700 spectrophotometer (Thermo Electron Corporation, MA, USA). Raman spectra were acquired using an INVIA spectrophotometer (Renishaw, UK). X-ray diffraction (XRD) patterns were recorded using an XRD analyzer (D8-FOCUS, Bruker, Karlsruhe, Germany). The magnetic properties were examined using a vibrating specimen magnetometer (VSM) (VSM7407, Lakeshore, USA). Transmission electron microscopy (TEM) images were captured using a JEOL (JEM-2010HR, Japan) transmission electron microscope. The amounts of analytes were determined using high performance liquid chromatography (HPLC)-UV (Agilent technologies 1260 Infinity) and the HPLC conditions were as follows: an acrylamide analytical column, a $\mathrm{C}_{18}$ column $250 \mathrm{~mm} \times 4.6 \mathrm{~mm}$ (5 $\mu \mathrm{m}$ particle, Waters, USA) column temperature, $20^{\circ} \mathrm{C}$; UV detection at $210 \mathrm{~nm}$; mobile phase, methanol/ $\mathrm{H}_{2} \mathrm{O}(5: 95, \mathrm{v} / \mathrm{v})$; flow rate, $1.0 \mathrm{~mL} \cdot \mathrm{min}^{-1}$; and injection volume, $20 \mu \mathrm{L}$.

\subsection{Preparation of magnetic graphene oxide $\left(\mathrm{GO}-\mathrm{Fe}_{3} \mathrm{O}_{4}\right)$}

GO was prepared from a natural graphite powder using a modified Hummers' method (Yeh, Syu, Cheng, Chang, \& Teng, 2010). In brief, $5 \mathrm{~g}$ of a graphite powder and $2.5 \mathrm{~g}$ of $\mathrm{NaNO}_{3}$ were added to a flask containing $120 \mathrm{~mL}$ of $\mathrm{H}_{2} \mathrm{SO}_{4}$ (95\%) and cooled in an ice bath with stirring. After the graphite powder was well dispersed, $15 \mathrm{~g}$ of $\mathrm{KMnO}_{4}$ was added gradually with stirring while maintaining the temperature of the mixture at $35^{\circ} \mathrm{C}$ for $60 \mathrm{~min} \cdot \mathrm{H}_{2} \mathrm{O}_{2}(3 \mathrm{~mL}$, $30 \%)$ and deionized water $(100 \mathrm{~mL})$ were slowly added over $30 \mathrm{~min}$ into the above reaction mixture at $90{ }^{\circ} \mathrm{C}$ with vigorous agitation. Finally, the resultant yellow-brown GO was washed with a $10 \%$ aqueous solution of $\mathrm{HCl}$ and distilled water until $\mathrm{pH}$ reached 7 , and was later dried at $60^{\circ} \mathrm{C}$ for $24 \mathrm{~h}$.

The $\mathrm{GO}-\mathrm{Fe}_{3} \mathrm{O}_{4}$ nanocomposite was synthesized according to the following solvothermal method (Ai, Zhang, \& Chen, 2011): $0.45 \mathrm{~g}$ of GO was completely dispersed by sonication in $70 \mathrm{~mL}$ of ethylene glycol for more than $3 \mathrm{~h}$. Next $1.4 \mathrm{~g}$ of $\mathrm{FeCl}_{3} \cdot 6 \mathrm{H}_{2} \mathrm{O}$ and $2.8 \mathrm{~g}$ of $\mathrm{NaAc}$ were added to the mixture. After stirring for approximately $30 \mathrm{~min}$, the mixture was transferred into a $100 \mathrm{~mL}$ autoclave vessel made of Teflon and stainless-steel and heated at $200{ }^{\circ} \mathrm{C}$ for $8 \mathrm{~h}$. The $\mathrm{GO}-\mathrm{Fe}_{3} \mathrm{O}_{4}$ nanocomposite obtained was thoroughly washed with ultrapure water and ethanol, and then freeze-dried.

The surface of the $\mathrm{GO}-\mathrm{Fe}_{3} \mathrm{O}_{4}$ nanocomposite was grafted with acrylic acid using the following procedure (Liu et al., 2011): briefly, 
$5 \mathrm{~mL}$ of the suspension containing $100 \mathrm{mg}$ of the $\mathrm{GO}-\mathrm{Fe}_{3} \mathrm{O}_{4}$ nanocomposites was added into $15 \mathrm{~mL}$ of ethanol with sonication. Next, $1 \mathrm{~mL}$ of AA was added into the above mixture, followed by incubation with shaking at a rate of $300 \mathrm{rpm}$ for $2 \mathrm{~h}$.

\subsection{Preparation of $A M-D S M I P S-G O-\mathrm{Fe}_{3} \mathrm{O}_{4}$}

The AM-based AM-DSMIPs-GO- $\mathrm{Fe}_{3} \mathrm{O}_{4}$ was prepared using a one-pot method using propionamide ( $\mathrm{PM}$ ) as the dummy template molecule, AA as the functional monomer, EGDMA as the crosslinker, and AIBN as the initiator in acetonitrile containing the surface supporting material $\mathrm{GO}-\mathrm{Fe}_{3} \mathrm{O}_{4}-\mathrm{AA}$. In a $100 \mathrm{~mL}$ flask, PM (73.09 $\mathrm{mg}, 1 \mathrm{mmol}$ ) and AA (288.2 $\mathrm{mg}, 4 \mathrm{mmol})$ were mixed for $6 \mathrm{~h}$ in the solvent acetonitrile $(60 \mathrm{~mL})$ for preassembly. Then GO$\mathrm{Fe}_{3} \mathrm{O}_{4}-\mathrm{AA}(80 \mathrm{mg})$ and EGDMA $(170 \mu \mathrm{L}, 0.9 \mathrm{mmol})$, were added into a three-necked flask. The pre-polymerization mixture was degassed in an ultrasonic bath for $10 \mathrm{~min}$, Nitrogen was passed through the solution for 30 min to remove oxygen, and the solution was then heated to $60{ }^{\circ} \mathrm{C}$ and maintained at this constant temperature AIBN $(0.062 \mathrm{~g}, 0.381 \mathrm{mmol})$ was added, and precipitation polymerization was allowed to proceed for $24 \mathrm{~h}$ under nitrogen stream. The AM-DSMIPs-GO- $\mathrm{Fe}_{3} \mathrm{O}_{4}$ particles were washed with a methanol:acetic acid mixture $(9: 1, v / v)$ to remove the template molecules and residual monomers. Finally, the particles were dried to a constant weight in vacuum at $55^{\circ} \mathrm{C}$. As a control, nonimprinted polymers (NIPs- $\mathrm{GO}-\mathrm{Fe}_{3} \mathrm{O}_{4}$ ) were prepared in the same manner but without adding the template molecules. Because there was no relevant literature describing the preparation of MIPs with specific recognition of acrylamide, we set up three groups with differing ratios of template molecules to functional monomers $(1: 2$, $1: 4$, and $1: 6)$ to identify AM-DSMIPs-GO- $\mathrm{Fe}_{3} \mathrm{O}_{4}$ with the best adsorption performance for recognition of acrylamide.

\subsection{Characterization of $\mathrm{AM}-\mathrm{DSMIPS}-\mathrm{GO}-\mathrm{Fe}_{3} \mathrm{O}_{4}$}

$\mathrm{GO}, \mathrm{GO}-\mathrm{Fe}_{3} \mathrm{O}_{4}$, and AM-DSMIPs-GO- $\mathrm{Fe}_{3} \mathrm{O}_{4}$ were characterized by via transmission electron microscopy (TEM), Fourier transform infrared (FT-IR) spectroscopy, X-ray diffraction (XRD), Raman spectroscopy and vibrating-sample magnetometry (VSM) (Huang et al., 2015; Roya, Patraa, Kumar, Madhuri, \& Prashant, 2015; Zubir et al., 2015; Han, Li, Wang, \& Chen, 2015).

\subsection{Adsorption experiments and evaluation of selectivity}

The binding ability of AM-DSMIPs- $\mathrm{GO}-\mathrm{Fe}_{3} \mathrm{O}_{4}$ was investigated in static, dynamic, and selective binding experiments (Dong et al., 2014; Hu et al., 2015; Li et al., 2015).The binding capacity and kinetic properties of AM-DSMIPs-GO- $\mathrm{Fe}_{3} \mathrm{O}_{4}$ and NIPs-GO- $\mathrm{Fe}_{3} \mathrm{O}_{4}$ toward acrylamide were determined as follows: $20 \mathrm{mg}$ polymer samples were dispersed in $10 \mathrm{~mL}$ flasks, each containing $2.0 \mathrm{~mL}$ of an acrylamide solution of various concentrations $(5,10,15,20$, $25,30,35,40$, and $45 \mu \mathrm{g} \cdot \mathrm{mL}^{-1}$ ), After incubation with shaking for $24 \mathrm{~h}$, the mixtures were separated by an external magnet and the supernatants were passed through a $0.45 \mu \mathrm{m}$ Millipore microfiltration membrane. Concentrations of acrylamide in the filtered supernatants were determined by HPLC-UV. The binding amounts of acrylamide were determined by subtracting the residual amounts in solution from the initial amounts according to the following equation:

$Q_{e}=\left(C_{0}-C_{e}\right) V / M$

Dynamic adsorption experiments were also conducted by monitoring the amounts of acrylamide in solution after different incubation periods $(5,10,15,20,25,30,60,90$, and $120 \mathrm{~min}$, with $C$ (acrylamide) of $40 \mu \mathrm{g} \cdot \mathrm{mL}^{-1}$ ), as calculated by means of the following formula:
$Q_{t}=\left(C_{0}-C_{t}\right) V / M$

where $Q_{e}$ and $Q_{t}\left(\mathrm{mg} \cdot \mathrm{g}^{-1}\right.$ ) are the binding capacity of the polymer and acrylamide, respectively, at equilibrium and at various time points, $\mathrm{t} ; C_{0}, C_{e}$ and $C_{t}\left(\mathrm{mg} \cdot \mathrm{L}^{-1}\right)$ are the adsorption concentrations of the solutions, initially, at equilibrium and after time respectively; $V(\mathrm{~mL})$ is the volume of the solution; and $W(\mathrm{~g})$ is the mass of polymers added to the solutions. The recognition ability of AM-DSMIPs$\mathrm{GO}-\mathrm{Fe}_{3} \mathrm{O}_{4}$ was evaluated using the imprinting factor $(\alpha)$, which is defined as follows:

$\alpha=Q_{\text {MIP }} / Q_{\text {NIP }}$

where $Q_{M I P}$ and $Q_{N I P}$ are the adsorption amounts of the templates.

At the same time, the selectivity of AM-DSMIPs- $\mathrm{GO}-\mathrm{Fe}_{3} \mathrm{O}_{4}$ was next demonstrated by a competitive binding assay. PM, AA, PA, $\mathrm{L}$-Asn, and ACA served as analogs in the analysis of the competitive recognition ability of AM-DSMIPs-GO- $\mathrm{Fe}_{3} \mathrm{O}_{4} .20 \mathrm{mg}$ polymers were added to $5 \mathrm{~mL}$ flasks containing $40 \mu \mathrm{g} \cdot \mathrm{mL}^{-1}$ acrylamide and one of five structural analogs, and then the solutions were incubated for $24 \mathrm{~h}$. Finally, the solution was centrifuged, filtered and analyzed. The selectivity factor was defined as

$\beta=Q_{\text {template }} / Q_{\text {analogue }}$.

Each group of experiments was analyzed three times in parallel.

Moreover, the adsorption isotherms and binding kinetics fitting analyses were discussed by the Langmuir, Freundlich, and Scatchard models (Zhu et al., 2012), as well as pseudo-first-order, and pseudo-second-order models (Alexandre, Scott, Anna, Kazuyoshi, \& Isao, 2000), respectively.

\subsection{The regeneration and reusability assays}

AM-DSMIPs-GO- $\mathrm{Fe}_{3} \mathrm{O}_{4}$ with adsorbed acrylamide was separated magnetically and then subjected to elution with $3.0 \mathrm{~mL}$ of methanol:acetic acid $(9: 1, \mathrm{v} / \mathrm{v})$ with rocking for $30 \mathrm{~min}$ to release acrylamide. The regenerated AM-DSMIPs-GO- $\mathrm{Fe}_{3} \mathrm{O}_{4}$ was reused in the adsorption experiments.

\subsection{Selective extraction and quantification of acrylamide in real samples}

Several heat-processed (including fried) food samples (potato chips, biscuit, fried instant noodles, and dough sticks) were purchased at a local market in Nanchang City. The food samples were ground into fine powders using a mortar and pestle. The samples $(2 \mathrm{~g})$, which were spiked or not spiked with different concentrations of standard acrylamide solutions ( $2 \mathrm{~mL}$, at 1,2 , or $4 \mathrm{ng} \cdot \mathrm{g}^{-1}$ ), were extracted using a methanol:water $(10 \mathrm{~mL})$ mixture for $30 \mathrm{~min}$. The solutions were then centrifuged and filtered to obtain the extract solution. AM-DSMIPs- $\mathrm{GO}-\mathrm{Fe}_{3} \mathrm{O}_{4}$ particles $(20 \mathrm{mg}$ ) were added into the extract solutions, which were next incubated with shaking at room temperature for $1 \mathrm{~h}$. A magnet was used to separate the AM-DSMIPs-GO- $\mathrm{Fe}_{3} \mathrm{O}_{4}$ particles from the solution. Supernatants were passed through a $0.45 \mu \mathrm{m}$ Millipore microfiltration membrane, and concentrations of acrylamide were determined by HPLC-UV. Next, acrylamide adsorbed onto the A M-DSMIPs-GO- $\mathrm{Fe}_{3} \mathrm{O}_{4}$ sorbent was eluted with $2 \mathrm{~mL}$ of methanol: acetic acid $(9: 1, v / v)$. Following desorption for $2 \mathrm{~h}$, acrylamide and the adsorbent were easily and rapidly separated using a magnet. The recovered amount of acrylamide was then determined by HPLC-UV spectrometry at $210 \mathrm{~nm}$ (Paleologos \& Kontominas, 2005; Tekkeli, Cem, \& Armağan, 2012). In addition, matrix interference was prevented by using AM-DSMIPs-GO- $\mathrm{Fe}_{3} \mathrm{O}_{4}$ as the extracting agent. The absorbance values were determined by subtracting absorbance of blank samples. All the experiments were performed in triplicate, and the data were expressed as mean values. 


\section{Results and discussion}

\subsection{Preparation of $A M-D S M I P S-G O-\mathrm{Fe}_{3} \mathrm{O}_{4}$}

Fig. 1 illustrates the synthesis route for AM-DSMIPs-GO- $\mathrm{Fe}_{3} \mathrm{O}_{4}$. GO was prepared by classic Hummers' method. GO- $\mathrm{Fe}_{3} \mathrm{O}_{4}$ nanocomposites were fabricated by a solvothermal method, where $\mathrm{FeCl}_{3} \cdot 6 \mathrm{H}_{2} \mathrm{O}$ served as the iron source, and sodium acetate as the reductant. $\mathrm{Fe}^{3+}$ was absorbed by the oxygen-containing functional groups of $\mathrm{GO}$, and $\mathrm{Fe}^{3+}$ was reduced to $\mathrm{Fe}_{3} \mathrm{O}_{4}$ by sodium acetate during the reaction. $\mathrm{GO}-\mathrm{Fe}_{3} \mathrm{O}_{4}$ nanocomposites were functionalized via a simple coordination reaction of the carboxyl group of AA with the oxygen-containing functional groups of GO and residual $\mathrm{Fe}^{3+}$ on the particle surface (Jeong, Teng, Wang, Yang, \& Xia, 2007; Shen et al., 2012) AM-DSMIPs-GO- $\mathrm{Fe}_{3} \mathrm{O}_{4}$ was then obtained through copolymerization in the presence of vinyl groupfunctionalized $\mathrm{GO}-\mathrm{Fe}_{3} \mathrm{O}_{4}-\mathrm{AA}, \mathrm{PM}, \mathrm{AA}$, and EGDMA. The molar ratio of templates and functional monomers is a critical factor for good imprinting efficiency. Different molar ratios of the template and functional monomers $(1: 2,1: 4$, and 1:6) were evaluated and optimized. The results revealed that AM-DSMIPs-GO- $\mathrm{Fe}_{3} \mathrm{O}_{4}$ made at the $1: 4$ ratio has the highest adsorption capacity toward acrylamide (Supplementary Table S1). This result was obtained probably because lower molar ratios yielded fewer binding sites in polymers and fewer template-monomer complexes, whereas the higher ratios produced a greater number of non-specific binding sites, diminishing the binding selectivity.

\subsection{Characterization of AM-DSMIPS-GO- $\mathrm{Fe}_{3} \mathrm{O}_{4}$}

Fig. 2B shows the representative TEM images of $\mathrm{GO}, \mathrm{GO}-\mathrm{Fe}_{3} \mathrm{O}_{4}$ and AM-DSMIPs-GO- $\mathrm{Fe}_{3} \mathrm{O}_{4}$, which showed smooth surfaces and layered structures in the $\mathrm{GO}$ sheets, suggesting that the $\mathrm{GO}$ sheets were exfoliated successfully [Fig. $2 \mathrm{~B}(\mathrm{a})$ ]. $\mathrm{Fe}_{3} \mathrm{O}_{4}$ nanoparticles also formed and were homogeneously anchored onto the GO sheets [Fig. 2B (b)]. Furthermore, MIPs were firmly attached to the surface of $\mathrm{GO}-\mathrm{Fe}_{3} \mathrm{O}_{4}$ after polymerization [Fig. 2B (c)].

Fig. 3A depicts the FT-IR spectra of $\mathrm{GO}, \mathrm{GO}-\mathrm{Fe}_{3} \mathrm{O}_{4}$, and AM-DS MIPs-GO- $\mathrm{Fe}_{3} \mathrm{O}_{4}$, all of which showed the $\mathrm{O}-\mathrm{H}$ stretching vibration adsorption peak at $3422.6 \mathrm{~cm}^{-1}$. For GO (curve 1), the peaks at $1623.3 \mathrm{~cm}^{-1}$ and $1190.4 \mathrm{~cm}^{-1}$ were assigned to the $\mathrm{C}=0$ stretching vibration of the carboxyl group and the $\mathrm{C}-\mathrm{O}$ stretching vibration peak of the epoxy group, respectively. The characteristic Fe-O stretching vibration peak at $564.7 \mathrm{~cm}^{-1}$ was observed in curve 2 , which proved that $\mathrm{Fe}_{3} \mathrm{O}_{4}$ nanoparticles were successfully anchored onto the GO sheets. In the FT-IR spectra of AM-DSMIPs-GO- $\mathrm{Fe}_{3} \mathrm{O}_{4}$, the intensities of absorption peak at 1623.3 and $1190.4 \mathrm{~cm}^{-1}$ strongly increased when the $\mathrm{GO}-\mathrm{Fe}_{3} \mathrm{O}_{4}$ particles were covered with MIPs that contained a large number of $\mathrm{C}=\mathrm{O}$ and $\mathrm{C}-\mathrm{O}$ groups in polyacrylamide units. All the peaks confirmed the successful synthesis of AM-DSMIPs-GO- $\mathrm{Fe}_{3} \mathrm{O}_{4}$.

$\mathrm{XRD}$ analyses were used to study the phases and structures of $\mathrm{GO}, \mathrm{GO}-\mathrm{Fe}_{3} \mathrm{O}_{4}$, and AM-DSMIPs-GO- $\mathrm{Fe}_{3} \mathrm{O}_{4}$ (Fig. 3B). GO showed a diffraction peak at $2 \theta=10.3$, which corresponds to a $d$-spacing at $12.57 \mathrm{~nm}$. The typical XRD pattern of peaks of $\mathrm{Fe}_{3} \mathrm{O}_{4}$ was observed at $2 \theta$ values of $30.2,35.5,43.0,53.6,57.0$, and 62.7 for GO- $\mathrm{Fe}_{3} \mathrm{O}_{4}$ and $\mathrm{AM}-\mathrm{DSMIPs}-\mathrm{GO}-\mathrm{Fe}_{3} \mathrm{O}_{4}$. In addition to these peaks, curve 3 corresponding to the AM-DSMIPs-GO- $\mathrm{Fe}_{3} \mathrm{O}_{4}$, showed a peak at $2 \theta=74.3$, indicating that the synthesis process and coexistence of $\mathrm{GO}$ and $\mathrm{Fe}_{3} \mathrm{O}_{4}$ in the recognition materials, did not change the XRD phase of $\mathrm{Fe}_{3} \mathrm{O}_{4}$.

Raman spectroscopy is a powerful method for characterization of carbon materials, including carbon nanotubes and graphene. Fig. $3 \mathrm{C}$ shows the Raman spectra of $\mathrm{GO}, \mathrm{GO}-\mathrm{Fe}_{3} \mathrm{O}_{4}$, and AM-DSMI Ps-GO- $\mathrm{Fe}_{3} \mathrm{O}_{4}$. All these samples yielded $\mathrm{D}$ bands (approximately $1340 \mathrm{~cm}^{-1}$ ) resulting from a disordered $\mathrm{sp}^{3}$ carbon structure and $\mathrm{G}$ bands (approximately $1560 \mathrm{~cm}^{-1}$ ) representing the $\mathrm{sp}^{2}$ ordered crystalline graphite-like structures. For all samples, the $\mathrm{I}_{(\mathrm{D})} / \mathrm{I}_{(\mathrm{G})}$ ratios of the $\mathrm{GO}, \mathrm{GO}-\mathrm{Fe}_{3} \mathrm{O}_{4}$, and AM-DSMIPs-GO- $\mathrm{Fe}_{3} \mathrm{O}_{4}$ were $0.83,1.06$, and 1.13 , respectively. Compared with the peak position of $\mathrm{GO}$, that of $\mathrm{GO}-\mathrm{Fe}_{3} \mathrm{O}_{4}$, and AM-DSMIPs-GO- $\mathrm{Fe}_{3} \mathrm{O}_{4}$ did not shift, but an increase in the $\mathrm{I}_{(\mathrm{D})} / \mathrm{I}_{(\mathrm{G})}$ ratio was observed, which reflected an increase in disorder present within the materials.

VSM characterization experiments with $\mathrm{GO}, \mathrm{GO}-\mathrm{Fe}_{3} \mathrm{O}_{4}$, and $\mathrm{A}$ $\mathrm{M}$-DSMIPs-GO- $\mathrm{Fe}_{3} \mathrm{O}_{4}$ were carried out at room temperature. Fig. 3D shows that the saturation magnetization values of $\mathrm{GO}$, $\mathrm{GO}-\mathrm{Fe}_{3} \mathrm{O}_{4}$, and AM-DSMIPs-GO- $\mathrm{Fe}_{3} \mathrm{O}_{4}$, gradually decreased to $35.1,14.2$, and $10.8 \mathrm{emu} \cdot \mathrm{g}^{-1}$ respectively, These saturation magne-

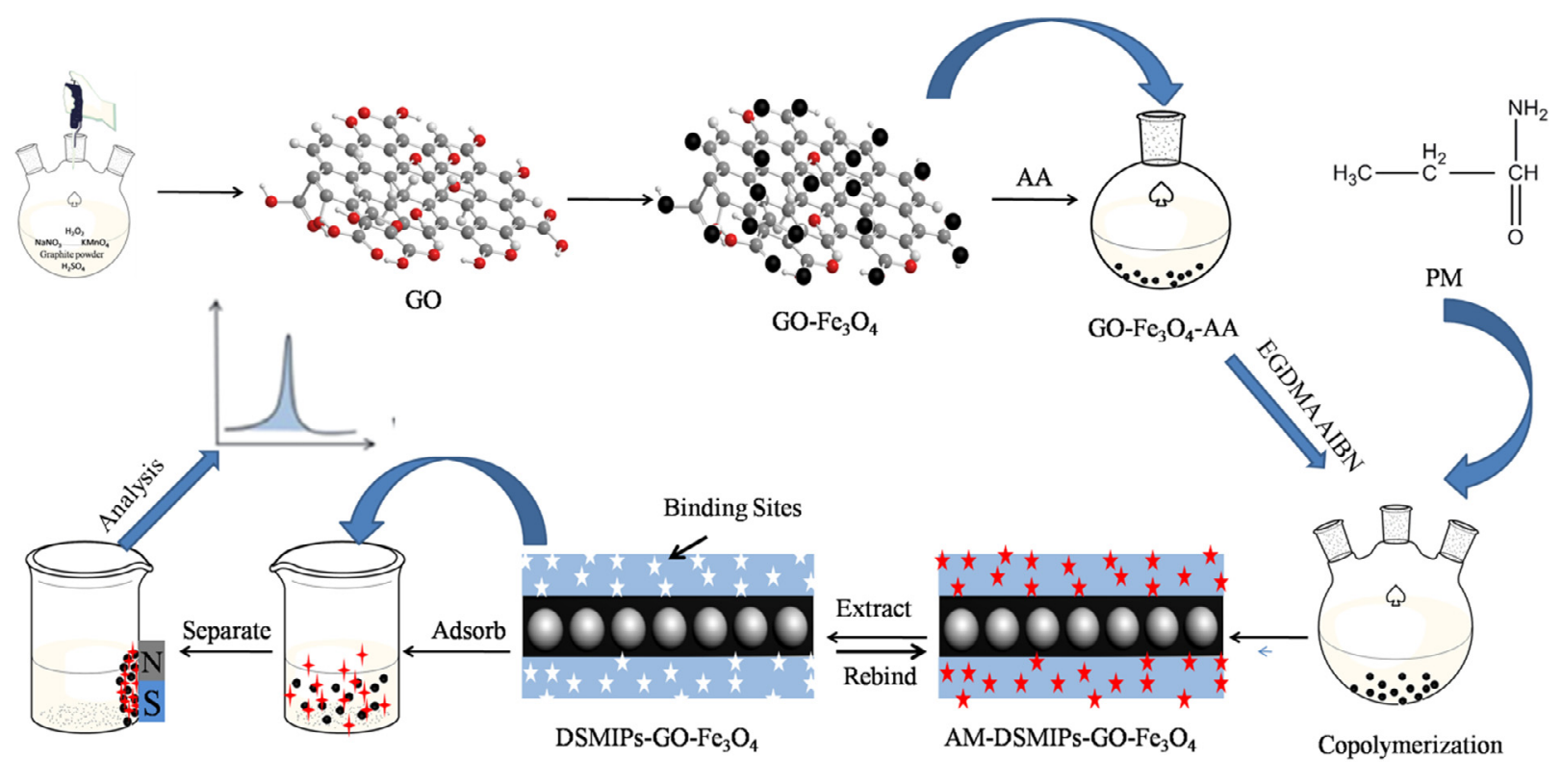

te Propionamide (PM) t Acrylamide (AM)

Fig. 1. Schematic illustration of the processes for preparation of $A M-D S M I P s-G O-\mathrm{Fe}_{3} \mathrm{O}_{4}$. 
A<smiles>C=CC(N)=O</smiles><smiles>CCC(N)=O</smiles><smiles>C=CC(=O)O</smiles>

Acrylamide (AM)

Propionamide (PM)

Acrylic acid (AA)<smiles>CCC(=O)O</smiles>

Propionic acid (PA)

$\mathrm{B}$

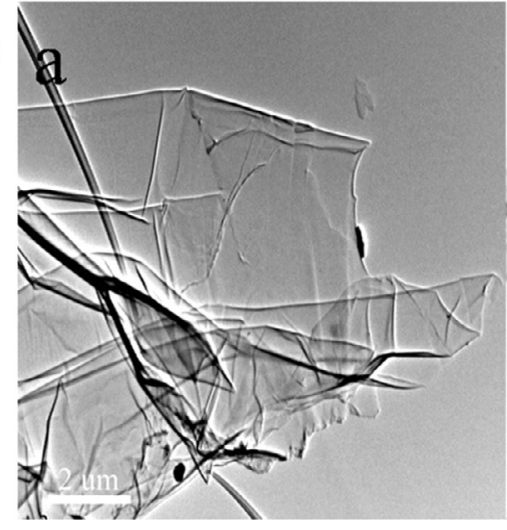

L-Asparagine (L-Asn)

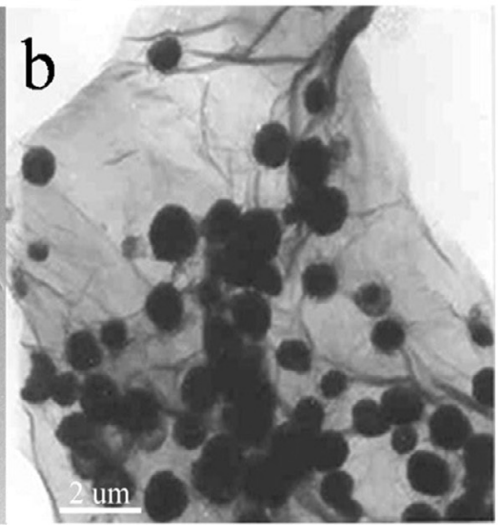

6-Aminocaproic acid (ACA)

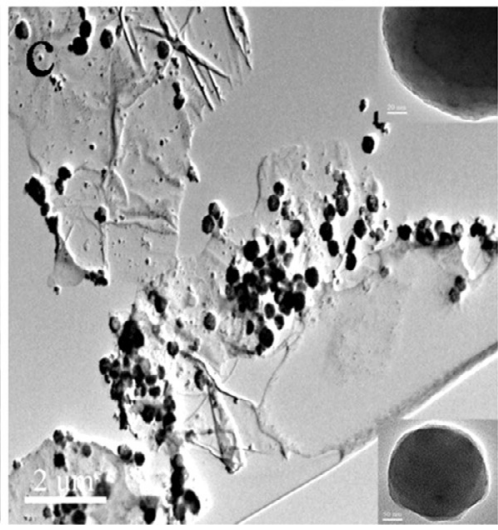

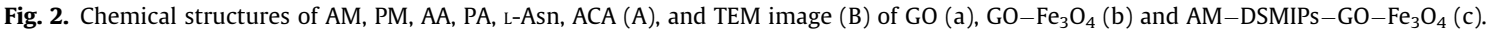

A
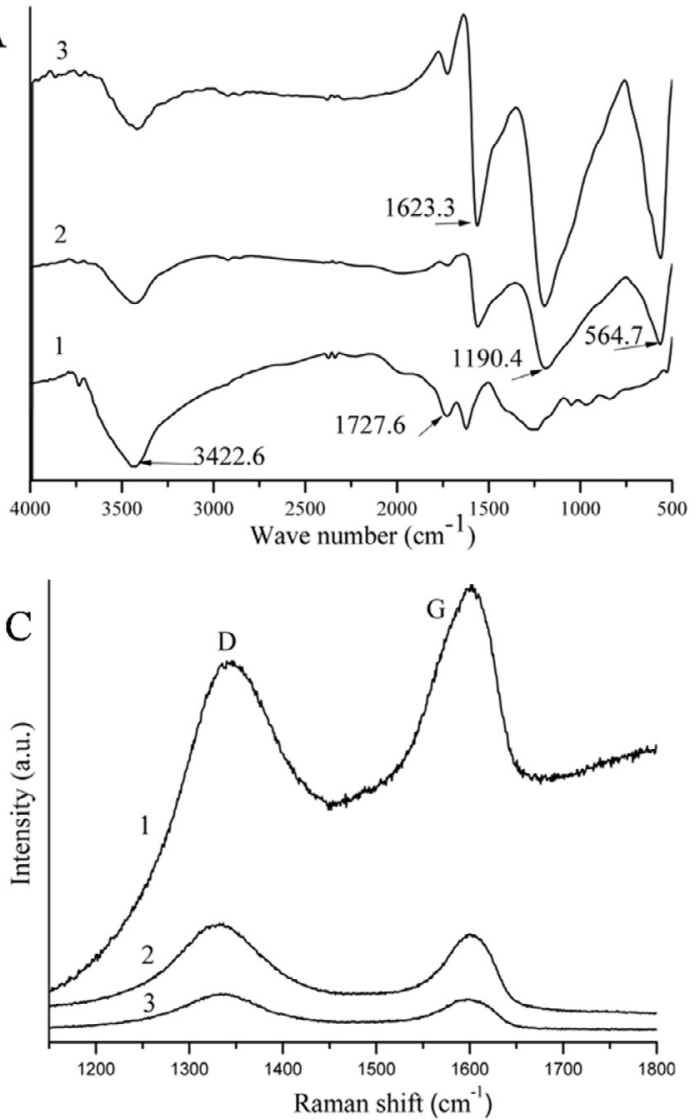
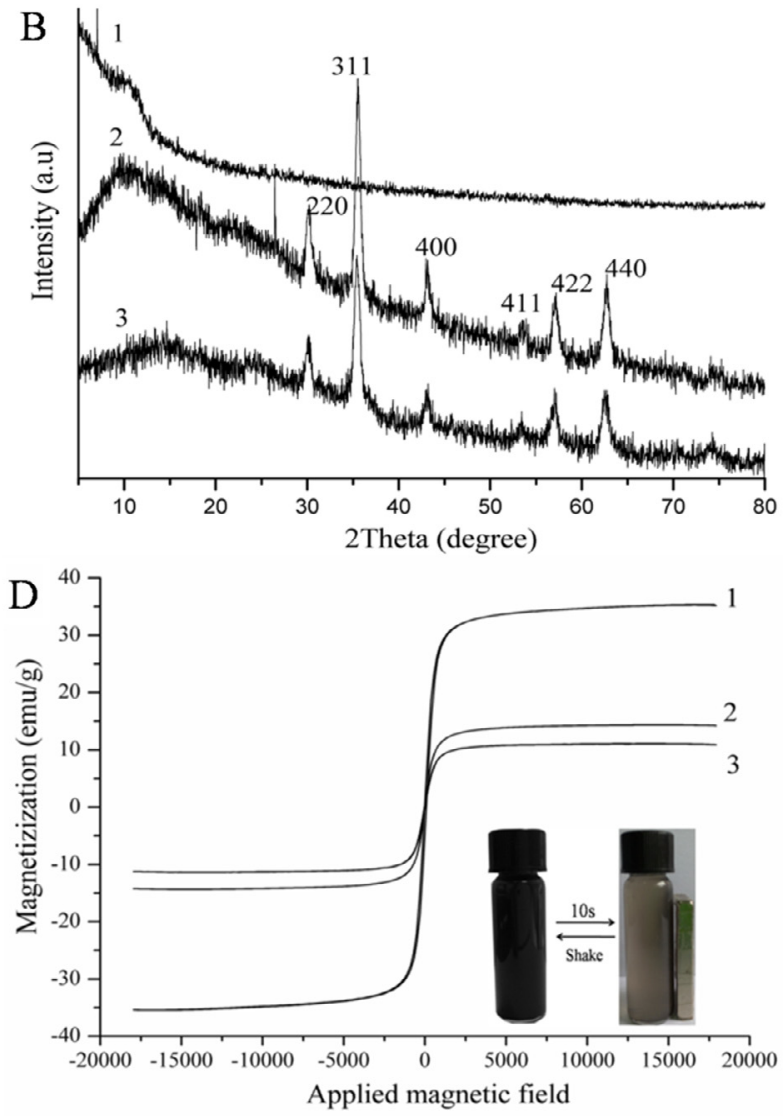

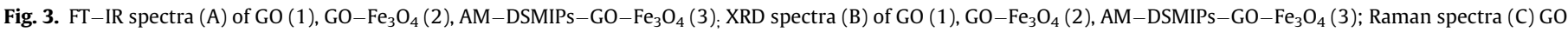
(1), $\mathrm{GO}-\mathrm{Fe}_{3} \mathrm{O}_{4}(2), \mathrm{AM}-\mathrm{DSMIPs}-\mathrm{GO}-\mathrm{Fe}_{3} \mathrm{O}_{4}$ (3); and VSM (D) $\mathrm{Fe}_{3} \mathrm{O}_{4}(1), \mathrm{GO}-\mathrm{Fe}_{3} \mathrm{O}_{4}(2), \mathrm{AM}-\mathrm{DSMIPs}-\mathrm{GO}_{-} \mathrm{Fe}_{3} \mathrm{O}_{4}(3)$. 
tization values were strong enough to ensure convenient magnetic separation. The saturation magnetization of AM-DSMIPs-GO-Fe $\mathrm{O}_{4}$ was lower because of the presence of GO and DSMIPs on the $\mathrm{Fe}_{3} \mathrm{O}_{4}$ surface. In addition, as seen in the inset, AM-DSMIPs-GO$\mathrm{Fe}_{3} \mathrm{O}_{4}$ nanocomposites can homogeneously disperse in aqueous solution, and the magnetic adsorbent was rapidly pulled to the vessel wall by a magnet.

\subsection{The adsorption experiment and evaluation of selectivity of AM- DSMIPS-GO- $\mathrm{Fe}_{3} \mathrm{O}_{4}$}

Fig. 4A shows the static binding isotherms of acrylamide toward AM-DSMIPs-GO- $\mathrm{Fe}_{3} \mathrm{O}_{4}$ and NIPs-GO- $\mathrm{Fe}_{3} \mathrm{O}_{4}$. The adsorption capacity of $\mathrm{AM}-\mathrm{DSMIPs}-\mathrm{GO}-\mathrm{Fe}_{3} \mathrm{O}_{4}$ for acrylamide rapidly increased with the increasing concentration and then slowed down when the concentration reached $40 \mu \mathrm{g} \cdot \mathrm{mL}^{-1}$. This stabilization was caused by the recognition sites on AM-DSMIPs-GO- $\mathrm{Fe}_{3} \mathrm{O}_{4}$, which were almost completely occupied by acrylamide when exceeding the equilibrium concentration. NIPs- $\mathrm{GO}-\mathrm{Fe}_{3} \mathrm{O}_{4}$ showed the same trend as AM-DSMIPs-GO- $\mathrm{Fe}_{3} \mathrm{O}_{4}$ did but with lower adsorption amounts because of the nonspecific recognition sites in NIPsGO- $\mathrm{Fe}_{3} \mathrm{O}_{4}$. The values of maximal binding capacity of AM-DSMIP s-GO- $-\mathrm{Fe}_{3} \mathrm{O}_{4}$ and NIPs-GO- $\mathrm{Fe}_{3} \mathrm{O}_{4}$ were 3.68 and $1.30 \mathrm{mg} \cdot \mathrm{g}^{-1}$, respectively. Hence, the obtained imprinting factor $(\alpha)$ equaled 2.83. The adsorption process was studied further using four classical isotherm models, namely, Langmuir, Freundlich, Scatchard, and Langmuir-Freundlich models. The corresponding equations and parameters of these models for the adsorption of acrylamide onto
AM-DSMIPs-GO- $\mathrm{Fe}_{3} \mathrm{O}_{4}$ or NIPs-GO- $\mathrm{Fe}_{3} \mathrm{O}_{4}$ are listed in Supplementary Table S2. Notably, the Langmuir-Freundlich model provided the best description of the adsorption. Given the correlation coefficient of 0.9911 , the parameters $\mathrm{Nt}, \alpha$, and $m$ were $6.38,0.052$, and 0.576 for AM-DSMIPs-GO- $-\mathrm{Fe}_{3} \mathrm{O}_{4}$ and 2.374, 0.028 , and 0.472 for NIPs-GO- $\mathrm{Fe}_{3} \mathrm{O}_{4}$. The relation between the parameters of AM-DSMIPs-GO- $\mathrm{Fe}_{3} \mathrm{O}_{4}$ and NIPs-GO- $\mathrm{Fe}_{3} \mathrm{O}_{4}$ indicates an excellent imprinting effect because of the presence of numerous specific binding sites on the AM-DSMIPs-GO- $\mathrm{Fe}_{3} \mathrm{O}_{4}$ surface.

Dynamic binding experiments were conducted to study the mass-transfer properties of AM-DSMIPs-GO-Fe $\mathrm{O}_{4}$ (Fig. 4B). The adsorption amounts of acrylamide on AM-DSMIPs-GO- $\mathrm{Fe}_{3} \mathrm{O}_{4}$ increased and reached an equilibrium within $30 \mathrm{~min}$. AM-DSMIP s-GO- $\mathrm{Fe}_{3} \mathrm{O}_{4}$ (3.68 $\left.\mathrm{mg} \cdot \mathrm{g}^{-1}\right)$ showed significantly better dynamic binding performance than NIPs-GO- $\mathrm{Fe}_{3} \mathrm{O}_{4}$ did $\left(1.30 \mathrm{mg} \cdot \mathrm{g}^{-1}\right)$. This finding suggests that the uniform spherical structure and large specific surface area of AM-DSMIPs-GO- $\mathrm{Fe}_{3} \mathrm{O}_{4}$ were favorable for rapid mass transfer. The increased adsorption and high equilibrium binding capacity were caused by the high proportion of surfaceimprinted sites and the large surface-to-volume ratio of AM-DS MIPs-GO- $\mathrm{Fe}_{3} \mathrm{O}_{4}$, allowing for high binding capacity and rapid mass transfer. Pseudo-first-order and pseudo-second-order kinetic models were used to analyze the kinetic data on AM-DSMIPs-GO- $\mathrm{Fe}_{3}$ $\mathrm{O}_{4}$ and NIPs-GO-Fe $\mathrm{O}_{4}$ to identify the rate-controlling and masstransfer mechanisms. The corresponding parameters were calculated by the two kinetic models (Supplementary Table S3). The pseudo-second-order model provided a better fit for the effect of time on the adsorption system as compared to the other kinetic
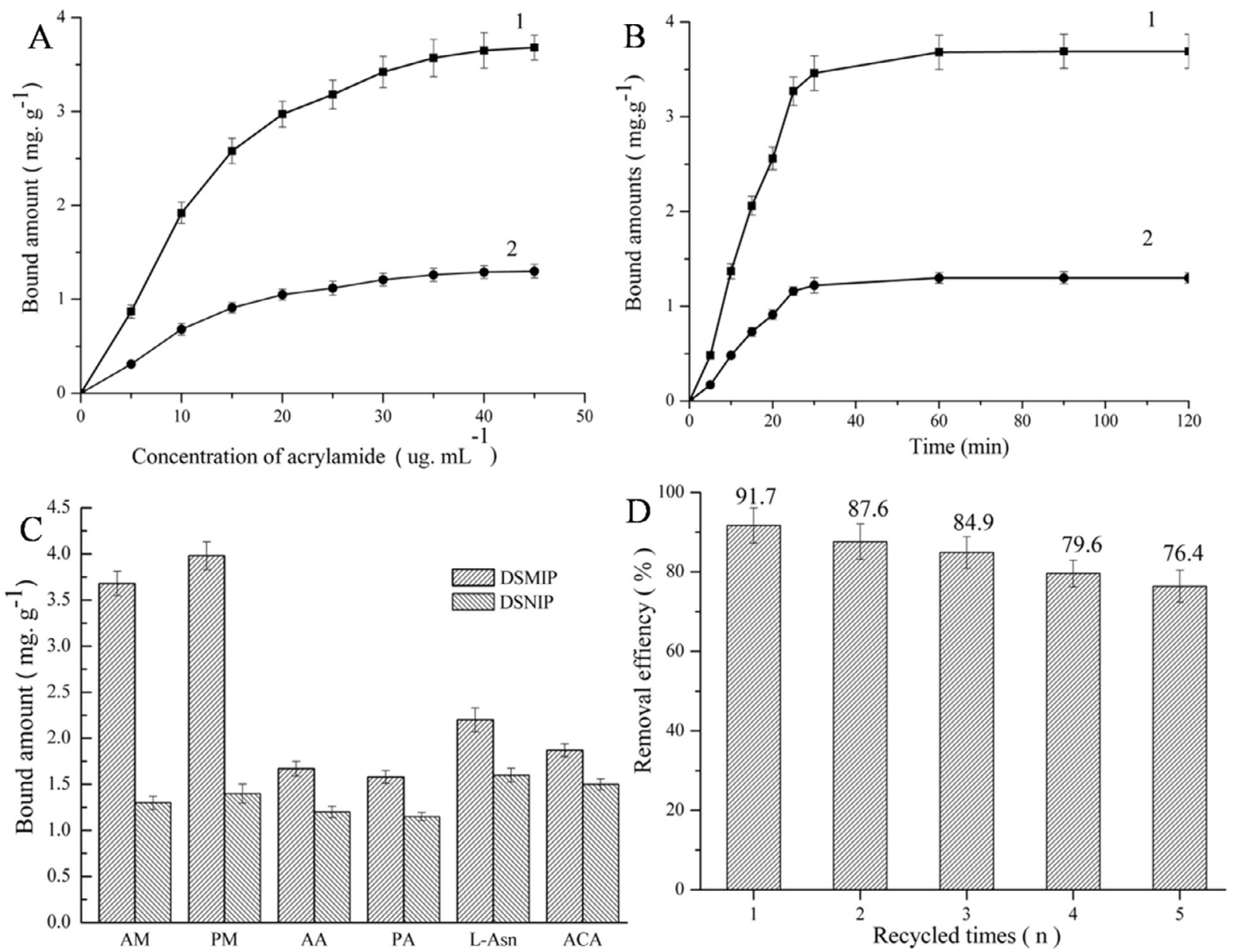

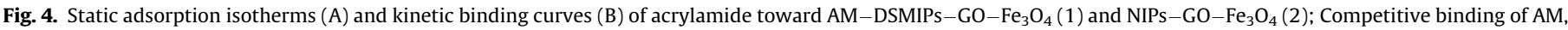
$\mathrm{PM}, \mathrm{AA}, \mathrm{PA}, \mathrm{L}-\mathrm{Asn}, \mathrm{ACA}$ on AM-DSMIPs-GO- $\mathrm{Fe}_{3} \mathrm{O}_{4}$ and NIPs-GO-Fe $\mathrm{O}_{4}(\mathrm{C})$; and reusability of AM-DSMIPs- $\mathrm{GO}-\mathrm{Fe}_{3} \mathrm{O}_{4}(\mathrm{D})$. 
models. The pseudo-second-order model yielded the most suitable correlation for adsorption, with the highest correlation coefficient: 0.9937 . The resulting rate constant $\left(k_{2}\right)$ was $0.0132 \mathrm{~g} \cdot(\mathrm{mg} \cdot \mathrm{min})^{-1}$, and equilibrium adsorption capacity $\left(Q_{e}\right)$ was $5.368 \mathrm{mg} \cdot \mathrm{g}^{-1}$. Thus, the adsorption can be deduced to follow the pseudo-secondorder kinetic model.

Among the tested molecules, the adsorption capacity of AM-D SMIPs-GO- $\mathrm{Fe}_{3} \mathrm{O}_{4}$ was the highest for PM (Fig. 4C). This phenomenon can be explained as follows: in the synthesis process, many recognition sites specific to the template were generated on the surface of AM-DSMIPs-GO- $\mathrm{Fe}_{3} \mathrm{O}_{4}$. As such, the template $\mathrm{PM}$ can be bound strongly to the particles. Interestingly, the adsorption amount of acrylamide was also high but slightly lower than that of $\mathrm{PM}$, because the shape and volume of acrylamide were very similar to those of PM (Fig. 2A). AM-DSMIPs-GO- $\mathrm{Fe}_{3} \mathrm{O}_{4}$ showed excellent recognition of acrylamide, indicating that $\mathrm{PM}$ is an ideal choice as a dummy template for acrylamide. By contrast, the adsorption amounts of AA, PA, L-Asn, and ACA were less than those of acrylamide and PM (Fig. 4C) because AA, PA, L-Asn, and ACA have shapes and volumes that are different from those of acrylamide and PM and cannot interact with AA by hydrogen bonding. The adsorption capacity values of NIPs-GO- $\mathrm{Fe}_{3} \mathrm{O}_{4}$ were very close and nonselective for the three compounds because selective recognition sites are absent in NIPs-GO- $\mathrm{Fe}_{3} \mathrm{O}_{4}$. The binding capacity values of AM-DSMIPs-GO-Fe $\mathrm{O}_{4}$ for AM, PM, AA, PA, L-Asn, and ACA were $3.68,3.98,1.67,1.58,2.2$, and $1.87 \mathrm{mg} \cdot \mathrm{g}^{-1}$, respectively. Accordingly, the imprinting factor values $(\alpha)$ of AM-DSMIPs-GO$\mathrm{Fe}_{3} \mathrm{O}_{4}$ for acrylamide, PM, AA, PA, L-Asn, and ACA were 2.83, 2.84, $1.39,1.37,1.38$, and 1.25 , respectively. The selectivity factor values $(\beta)$ of AM-DSMIPs-GO-Fe $\mathrm{O}_{4}$ for PM, AA, PA, L-Asn, and ACA were $0.92,2.20,2.33,1.67$, and 1.97 , respectively, indicating that AMDSMIPs-GO- $\mathrm{Fe}_{3} \mathrm{O}_{4}$ has a highly specific recognition ability toward acrylamide.

\subsection{The regeneration and reusability assays}

Additionally, the reusability of AM-DSMIPs-GO- $\mathrm{Fe}_{3} \mathrm{O}_{4}$ was evaluated, and the results suggested that it can offer great cost benefit combinations for further applications. As shown in Fig. 4D the recovery remained at $76.4 \%$ after five adsorption-desorption cycles. Consequently, the resulting AM-DSMIPs-GO- $\mathrm{Fe}_{3} \mathrm{O}_{4}$ was efficiently reusable without a substantial decrease in the adsorption capacity for acrylamide. Therefore, this simple, rapid, reliable, and reusable $\mathrm{AM}-\mathrm{DSMIPs}-\mathrm{GO}-\mathrm{Fe}_{3} \mathrm{O}_{4}$ shows practical suitability for

\section{Table 1}

Recovery of acrylamide from potato chips, biscuit, fried instant noodles, and dough sticks using $\mathrm{AM}-\mathrm{DSMIPs}-\mathrm{GO}-\mathrm{Fe}_{3} \mathrm{O}_{4}$ as adsorbents and followed by HPLC-UV analysis.

\begin{tabular}{|c|c|c|c|c|}
\hline \multirow[t]{2}{*}{ Sample } & Concentration & Added & Determined & Recovery \\
\hline & $\left(\mathrm{ng} \cdot \mathrm{g}^{-1}\right)$ & $\left(\mathrm{ng} \cdot \mathrm{g}^{-1}\right)$ & $\left(\mathrm{ng} \cdot \mathrm{g}^{-1}\right)$ & (\%) \\
\hline \multirow[t]{4}{*}{ Potato chips } & 0.67 & - & - & - \\
\hline & & 1 & 1.54 & 91.9 \\
\hline & & 2 & 2.47 & 92.3 \\
\hline & & 4 & 4.38 & 93.7 \\
\hline \multirow{4}{*}{ Biscuit } & 0.37 & - & - & - \\
\hline & & 1 & 1.23 & 89.6 \\
\hline & & 2 & 2.19 & 92.5 \\
\hline & & 4 & 4.01 & 91.7 \\
\hline \multirow[t]{4}{*}{ Fried instant noodles } & 0.46 & - & - & - \\
\hline & & 1 & 1.27 & 87.4 \\
\hline & & 2 & 2.17 & 88.1 \\
\hline & & 4 & 4.03 & 90.4 \\
\hline \multirow[t]{4}{*}{ Dough sticks } & 0.13 & - & - & - \\
\hline & & 1 & 0.98 & 86.7 \\
\hline & & 2 & 2.01 & 94.3 \\
\hline & & 4 & 3.63 & 87.9 \\
\hline
\end{tabular}

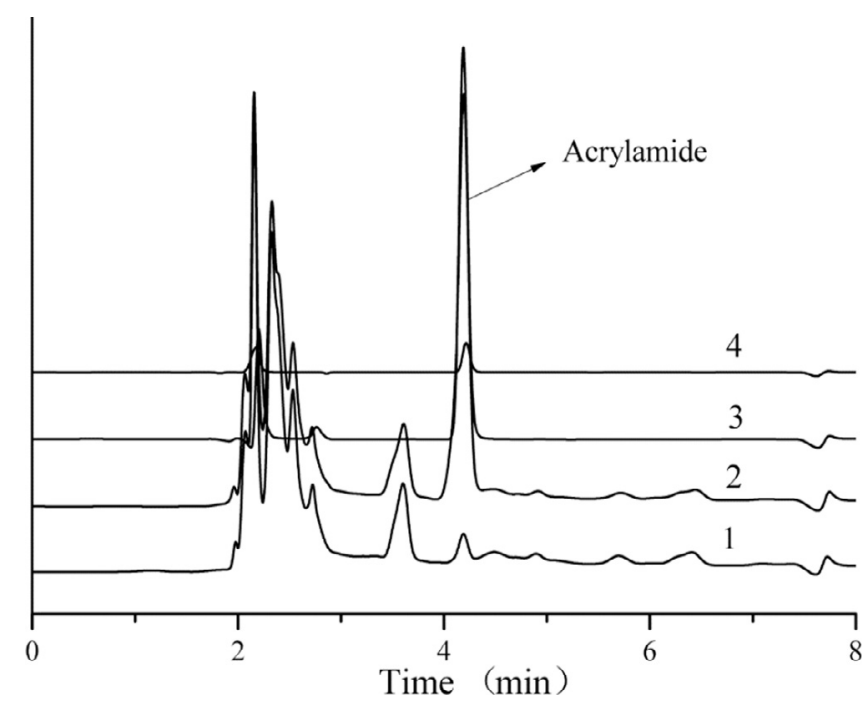

Fig. 5. HPLC-UV chromatograms of food samples. The samples were processed as follows: not spiked (1), spiked with $4 \mathrm{ng} \cdot \mathrm{g}^{-1}$ acrylamide and without extraction (2), spiked with $4 \mathrm{ng} \cdot \mathrm{g}^{-1}$ acrylamide and with AM-DSMIPs-GO- $\mathrm{Fe}_{3} \mathrm{O}_{4}$ extraction (3) spiked with $4 \mathrm{ng} \cdot \mathrm{g}^{-1}$ acrylamide and the remaining solution after extraction (4).

highly selective and sensitive acrylamide analyses in complicated matrices.

\subsection{Selective extraction and quantification of acrylamide in real-world samples}

To further assess the practical applicability of AM-DSMIPs-GO$\mathrm{Fe}_{3} \mathrm{O}_{4}$, several heat-processed (including fried) food products (potato chips, biscuit, fried instant noodles, and dough sticks) were used as real-world samples for analysis. Table 1, summarizes the results on the three spiked acrylamide concentrations of 1,2 , and $4 \mathrm{ng} \cdot \mathrm{g}^{-1}$, The extraction recovery provided by AM-DSMIPs-GO-F $\mathrm{e}_{3} \mathrm{O}_{4}$ ranged from $86.7-94.3 \%$ with relative standard deviations of $3.28 \%$ to $4.85 \%$. The resulting limits of detection and quantification were 15 and $49.5 \mu \mathrm{g} \cdot \mathrm{kg}^{-1}$ at signal-to-noise ratios of 3 and 10 , respectively. Fig. 5 presents the typical HPLC-UV chromatograms. Matrix effects were reduced, and the added acrylamide was effectively concentrated by AM-DSMIPs- $\mathrm{GO}-\mathrm{Fe}_{3} \mathrm{O}_{4}$, indicating its high selectivity and enrichment ability toward acrylamide.

\section{Conclusions}

A new type of DSMIPs-GO-Fe $\mathrm{O}_{4}$ was developed for the specific recognition and highly effective removal of acrylamide from complicated matrices. GO was utilized to improve the adsorption capacity and $\mathrm{Fe}_{3} \mathrm{O}_{4}$ nanoparticles were used for facile separation. The characteristics, binding properties and imprinting ability of DSMIPs-GO- $\mathrm{Fe}_{3} \mathrm{O}_{4}$ were systematically analyzed. DSMIPs-GO$\mathrm{Fe}_{3} \mathrm{O}_{4}$ shows faster adsorption and desorption dynamics and higher selectivity than those of traditional MIPs. The smart extraction of acrylamide by AM-DSMIPs-GO- $\mathrm{Fe}_{3} \mathrm{O}_{4}$ from food samples such as potato chips, biscuits, fried instant noodles, and dough sticks was evaluated, and showed a great potential for the analysis/removal of acrylamide in complicated matrices.

\section{Acknowledgements}

This work was supported by the National Natural Science Foundation of China (21667018 and 31660482), National Key Technology Research and Development Program of the Ministry of Science and Technology of China (No. 2013BAD19B02) and Graduate student innovation fund of Jiangxi Province (YC2016-B013). 


\section{Appendix A. Supplementary data}

Supplementary data associated with this article can be found, in the online version, at http://dx.doi.org/10.1016/j.foodchem.2016. 10.101 .

\section{References}

Ai, L. H., Zhang, C. Y., \& Chen, Z. L. (2011). Removal of methylene blue from aqueous solution by a solvothermal-synthesized graphene/magnetite composite. Journal of Hazardous Materials, 192, 1515-1524.

Alexandre, R., Scott, M., Anna, E. S., Kazuyoshi, Y., \& Isao, K. (2000). Fluorescence detection of $\beta$-estradiol using a molecularly imprinted polymer. Analytica Chimica Acta, 405, 23-29.

Carpinteiro, J., Quintana, J. B., Rodríguez, I., Carro, A. M., Lorenzo, R. A., \& Cela, R. (2004). Applicability of solid-phase microextraction followed by on-fiber silylation for the determination of estrogens in water samples by gas chromatography-tandem mass spectrometry. Journal of Chromatography A, $1056,179-185$.

Chen, S. N., Li, X., Zhao, Y. Y., Chang, L. M., \& Qi, J. Y. (2014). High performance surface-enhanced raman scattering via dummy molecular imprinting onto silver microspheres. Chemical Communications, 50, 14331-14333.

Chen, L. X., Xu, S. F., \& Li, J. H. (2011). Recent advances in molecular imprinting technology: Current status, challenges and highlighted applications. Chemical Society Reviews, 40, 2922-2942.

Donald, S., Bronislaw, L., \& Andrew, T. (2004). Food chemistry: Acrylamide is formed in the Maillard reaction. Nature, 419, 448-449.

Dong, R. C., Li, J. H., Xiong, H., Lu, W. H., Peng, H. L., \& Chen, L. X. (2014). Thermosensitive molecularly imprinted polymers on porous carriers: Preparation, characterization and properties as novel adsorbents for bisphenol A. Talanta, 130, 182-191.

Han, S., Li, X., Wang, Y., \& Chen, S. N. (2015). Multifunctional imprinted polymers based on CdTe/CdS and magnetic graphene oxide for selective recognition and separation of p-t-octylphenol. Chemical Engineering Journal, 271, 87-95.

Hu, C. H., Deng, J., Zhao, Y. B., Xia, L. S., Huang, K. H., \& Ni, S. Q. (2014). A novel coreshell magnetic nano-sorbent with surface molecularly imprinted polymer coating for the selective solid phase extraction of dimetridazole. Food Chemistry, $158,366-373$.

Hu, X., Xie, L. W., Guo, J. F., Li, H., Jiang, X. Y., Zhang, Y. P., \& Shi, S. Y. (2015). Hydrophilic gallic acid-imprinted polymers over magnetic mesoporous silica microspheres with excellent molecular recognition ability in aqueous fruit juices. Food Chemistry, 179, 206-212.

Huang, Y. H., Wang, Y. Z., Pan, Q., Wang, Y., Ding, X. Q., Xu, K. J., \& Qian, N. L. (2015) Magnetic graphene oxide modified with choline chloride-based deep eutectic solvent for the solid-phase extraction of protein. Analytica Chimica Acta, 877, 90-99.

IARC. (1994). Acrylamide. Monographs on the evaluation of carcinogenic risks to humans: Some industrial chemicals (Vol. 60, pp. 389-433). Lyon, France.

Jeong, U. Y., Teng, X. W., Wang, Y., Yang, H., \& Xia, Y. N. (2007). Superparamagnetic colloids: Controlled synthesis and niche applications. Advanced Materials, 2007 (19), 33-60.

Li, J. H., Dong, R. C., Wang, X. Y., Xiong, H., Xu, S. F., Shen, D. Z., \& Chen, L. X. (2015). One-pot synthesis of magnetic molecularly imprinted microspheres by RAFT precipitation polymerization for the fast and selective removal of $17 \beta$-estradiol. RSC Advances, 5, 10611-10688.

Li, Y., Li, X., Dong, C., Qi, J., \& Han, X. (2010). A graphene oxide-based molecularly imprinted polymer platform for detecting endocrine disrupting chemicals. Carbon, 48, 3427-3433.

Lin, S. C., Gan, N., Zhang, J. B., Chen, X. D., Cao, Y. T., \& Li, T. H. (2015). A novel reductive graphene oxide-based magnetic molecularly imprinted poly (ethylene-co-vinyl alcohol) polymers for the enrichment and determination of polychlorinated biphenyls in fish samples. Journal of Molecular Recognition, 28, 359-368.

Liu, B. H., Han, M. Y., Guan, G. J., Wang, S., Liu, R., \& Zhang, Z. (2011). Highlycontrollable molecular imprinting at superparamagneticiron oxide nanoparticles for ultrafast enrichment and separation. The Journal of Physical Chemistry C, 115, 17320-17327.

Luo, J., Jiang, S., \& Liu, X. (2013). Efficient one-pot Synthesis of mussel-inspired molecularly imprinted polymer coated graphene for protein-specific recognition and fast separation. The Journal of Physical Chemistry C, 117, 18448-18456.

Mastovska, K., \& Lehotay, S. J. (2006). Rapid sample preparation method for LC-MS/ MS or GC-MS analysis of acrylamide in various food matrices. Journal of Agricultural and Food Chemistry, 54, 7001-7008.

Mendel, Friedman. (2003). Chemistry, biochemistry, and safety of acrylamide a review. Journal of Agricultural and Food Chemistry, 51, 4504-4526.

Milan, F., Daniel, R., Iva, D., \& Fernando, R. (2014). Analytical evaluation of a highthroughput enzyme-linked immunosorbent assay for acrylamide determination in fried foods. Talanta, 123, 146-150.

Ning, F. J., Peng, H. L., Dong, L. L., Zhang, Z., Li, J. H., Chen, L. X., \& Xiong, H. (2014) Preparation and characterization of superparamagnetic molecularly imprinted polymers for selective adsorption and separation of vanillin in food samples. Journal of Agricultural and Food Chemistry, 62, 11138-11145.

Ning, F. J., Peng, H. L., Li, J. H., Chen, L. X., \& Xiong, H. (2014). Molecularly imprinted polymer on magnetic graphene oxide for fast and selective extraction of $17 \beta-$ estradiol. Journal of Agricultural and Food Chemistry, 62, 7436-7443.

Paleologos, E. K. \& Kontominas, M. G. (2005). Determination of acrylamide and methacrylamide by normal phase high performance liquid chromatography and UV detection. Journal of Chromatography A, 1077, 128-135.

Roya, E., Patraa, S., Kumar, D., Madhuri, R., \& Prashant, K. (2015). Multifunctional magnetic reduced graphene oxide dendrites: Synthesis, characterization and their applications. Biosensors and Bioelectronics, 68, 726-735.

Shen, J. F., Yan, B., Li, T., Long, Y., Li, N., \& Ye, M. X. (2012). Mechanical, thermal and swelling properties of poly (acrylic acid)-graphene oxide composite hydrogels. Soft Matter, 8, 1831-1836.

Swedish National Food Administration. (2002). Information about acrylamide in food. <http://www.slv.se>.

Tekkeli, S. E. K., Cem, Q., \& Armağan, Q. (2012). A review of current methods for the determination of acrylamide in food products. Food Analytical Methods, 5, 29-39.

Wang, S., Quan, Y., Lee, N., \& Kennedy, I. (2006). Rapid determination of fumonisin B1 in food samples by enzyme-linked immunosorbent assay and colloidal gold immunoassay. Journal of Agricultural and Food Chemistry, 54, 2491-2495.

Xie, L. W., Guo, J. F., Zhang, Y. P., Hua, Y. C., You, Q. P., \& Shi, S. Y. (2015). Novel molecular imprinted polymers over magnetic mesoporous silica microspheres for selective and efficient determination of protocatechuic acid in Syzygium aromaticum. Food Chemistry, 178, 18-25.

Xu, S. F., Lu, H. Z., Li, J. H., \& Chen, L. X. (2013). Dummy molecularly imprinted polymers-capped CdTe quantum dots for the fluorescent sensing of 2,4,6Trinitrotoluene. Applied Materials E Interfaces, 5, 8146-8154.

Yeh, T. F., Syu, J. M., Cheng, C., Chang, T. H., \& Teng, H. S. V. (2010). Graphite oxide as a photocatalyst for hydrogen production from water. Advanced Functional Materials, 20, 2255-2262.

Zhang, W. F., Deng, Z. F., Zhao, W. J., Guo, L., Tang, W., Du, H. F., ... Zhang, S. S. (2014) Determination of trace acrylamide in starchy foodstuffs by HPLC using a novel mixed-mode functionalized calixarene sorbent for solid-phase extraction cleanup. Journal of Agricultural and Food Chemistry, 62, 6100-6107.

Zhu, J., Wei, S., Gu, H., Rapole, S. B., Wang, Q., Luo, Z., ... Guo, Z. (2012). One-pot synthesis of magnetic graphene nanocomposites decorated with core@doubleshell nanoparticles for fast chromium removal. Environmental Science $\mathcal{E}$ Technology, 46, 977-985.

Zubir, N. A., Yacou, C., Motuzas, J., Zhang, X. W., Zhao, X. S., \& Costa, J. D. (2015). The sacrificial role of graphene oxide in stabilizing a Fenton-like catalyst $\mathrm{GO}-\mathrm{Fe}_{3} \mathrm{O}_{4}$. Chemical Communications, 51, 9291-9293. 